\title{
Type and Frequency of Opioid Pain Medications Returned for Disposal
}

\author{
Grace C. Welham • Jeanine K. Mount • \\ Aaron M. Gilson
}

Published online: 4 March 2015

(c) The Author(s) 2015. This article is published with open access at Springerlink.com

\begin{abstract}
Prescription opioids have increasingly been involved in overdose deaths and treatment admissions. Disposal programs may play an important role in curbing this trend. The objectives of this study were to: (1) quantify the prescription opioids returned for disposal to a local takeback program, and (2) explore selected drug characteristics that may predict the quantity of unused opioids. Leftover prescription opioid medications returned for disposal to a community drug take-back event were quantified and analyzed according to controlled substances schedule, formulation, number of active ingredients, and directions for use. Days' supply of medication remaining, calculated using the number of dosage units remaining divided by the maximum number of dosage units per day allowed by the prescriber, was the primary outcome variable. Opioid prescriptions returned for disposal had greater than $60 \%$ of the amount dispensed remaining unused. Short-acting C-II and C-III combination opioids accounted for greater than $80 \%$ of the prescriptions returned. Day supply dispensed was the strongest predictor of day supply remaining, regardless of
\end{abstract}

G. C. Welham $(\bowtie) \cdot$ J. K. Mount

Social Administrative Sciences Division, School of Pharmacy, University of Wisconsin-Madison, 777 Highland Avenue,

Madison, WI 53705, USA

e-mail: welham@wisc.edu

Present Address:

J. K. Mount

Department of Pharmacy and Health Systems Sciences, School of Pharmacy, Northeastern University, 360 Huntington Ave., Boston, MA 02115, USA

A. M. Gilson

UW Comprehensive Cancer Center, School of Medicine and Public Health, University of Wisconsin-Madison, Madison, WI 53706, USA other drug characteristics. These findings indicate that disposal programs are effective at removing unused medication from patient homes. To reduce leftover medication, prescriber education programs should address the amount to be prescribed. Continual monitoring of quantities prescribed and returned for disposal may be useful in evaluating the effects of these programs on leftover medication. Further research on drug characteristics may inform prescribing practices and reduce leftover medication.

\section{Key Points}

Opioid prescriptions returned for disposal had $>60 \%$ of the amount dispensed remaining unused.

Day supply dispensed was the strongest predictor of day supply remaining.

\section{Introduction}

Nonmedical use (abuse, misuse, and addiction) of prescription opioids results in serious public health consequences as evidenced by increased opioid-related treatment admissions [15] and escalating mortality [6]. In 2007, poisoning became the second leading cause of accidental death in the USA [4]. This trend is largely attributed to prescription opioid overdose, which has increased threefold since 1999 [20]. Admissions for treatment of prescription opioid abuse increased fivefold (from 1 to $5 \%$ ) between 1997 and 2007 [18], and an additional $16 \%$ between 2008 and 2009 [19]. Furthermore, survey and risk assessment data indicate that friends and relatives are the primary sources of nonmedically used opioids [5, 12, 17], 
highlighting the importance of understanding and reducing the volume of leftover prescription opioids that are available for nonmedical use.

Multiple federal agencies have recognized the importance of reducing prescription drug abuse, misuse, and addiction. The Office of National Drug Control Policy's (ONDCP) 2011 Prescription Drug Abuse Prevention Plan (the Plan) [14] focused on prescription opioids as a drug class due to both the increase in the number of opioid prescriptions filled annually in the USA and trends in prescription opioid overdose deaths. The Plan identified multiple strategies for reducing morbidity and mortality associated with nonmedical opioid use, including: (1) education of patients, youths and their parents, and healthcare practitioners, primarily through risk evaluation and mitigation strategies (REMS), (2) tracking and monitoring through state-authorized prescription drug monitoring programs (PDMPs), and (3) enforcement against diversion-related activities such as "doctor shopping" and "pill mills".

The final major strategy identified in the Plan was disposal of leftover medications as a way to reduce the volume of medication available for illicit use. "Take-back" programs are one mechanism for legally collecting unwanted and expired medications from households for disposal. These programs are still relatively new phenomena in the USA, and began as local efforts with the state and federal governments merely enforcing existing hazardous waste or transportation regulations [9]. The federal government's growing recognition of the importance of collection and disposal of unwanted medications is further evidenced in the Environmental Protection Agency's mailback program [9] and the passing of the Secure and Responsible Drug Disposal Act of 2010, which led to changes in the Drug Enforcement Administration's rules and regulations. The new regulations, effective 9 October 2014, now allow take-back programs to accept controlled substances for the purpose of disposal [8].

Take-back programs can offer a unique window for learning about leftover medications, which remain in households and are available for potential misuse. The ultimate fate of all prescriptions written and dispensed is completely unknown, given that patients may consume all, some, or none of a medication. Examining prescriptions collected through take-back programs allows researchers to identify, quantify, and explore factors associated with medications that have been prescribed and dispensed but that remain unconsumed by patients. Such understanding can assist in identifying areas of need and strategies for interventions aimed at reducing availability of unused prescription medications.

This study aims to (1) quantify the prescription opioids returned for disposal to a local take-back program, and (2) explore selected drug characteristics that may predict the quantity of unused opioids. The overarching goal of this study is informing initiatives of public and private organizations regarding opioid-related policies and practices.

\section{Methods}

\subsection{Data Collection}

Data were collected during a 4-h medication take-back event known as MedDrop ${ }^{\mathrm{TM}}$ in Dane County, WI, USA. At the time, MedDrop ${ }^{\mathrm{TM}}$ was a series of biannual collection events, held as a drive-through service where volunteers collected unwanted medications for disposal from drivers, who represented households.

At the event, 761 households returned over $1500 \mathrm{lbs}$ $(680 \mathrm{~kg})$ of medications for disposal. Controlled substances comprised $160 \mathrm{lbs}(72.5 \mathrm{~kg} ; 10.7 \%)$ of the total returned, which filled 30 gallons $(113.5 \mathrm{~L})$. The weight and volume reported includes only medication and as little packaging as possible. Of the controlled substances, 818 prescriptions were for opioid pain medications. Of these, 151 prescriptions were visually identified by pharmacists as opioids, but were missing prescription labels, and were excluded from data collection. Fifty-seven prescriptions were excluded because they are listed by the DEA as Schedule IV (C-IV) prescriptions (propoxyphene-containing products $[n=49]$, tramadol $[n=8])$. Five prescriptions were excluded because they are used for conditions other than generalized pain (butorphanol $[n=1]$, hydrocodone/guaifenasin or codeine/guaifenasin $[n=4])$. This study focuses on the remaining 605 Schedule II (C-II) and Schedule III (C-III) opioid prescriptions returned for disposal.

Data were recorded by trained pharmacy students. Items of information recorded from labels were: drug name and strength; date dispensed; brand name or generic product; directions for use; quantity dispensed; and quantity remaining (determined by counting the number of dosage units in the returned prescription bottle).

To protect privacy, all households were advised to remove or darken protected health information (PHI) from prescription labels prior to returning prescriptions for disposal. Volunteers were also required to sign a confidentiality agreement, should any PHI remain visible. The University of Wisconsin-Madison Social and Behavioral Sciences Institutional Review Board exempted this study from review.

\subsection{Variables}

Days' supply of a medication is a measure commonly used by pharmacists and insurers to determine the length of time a prescription should last before the medication is used up 
and/or a refill is issued $[2,8,10,11,21]$. Days' supply of medications accounts for more information regarding how a medication was used than other measures of medications remaining. It is based on the amount of a medication that a patient has been prescribed to safely take each day and is calculated as:

Days' supply $=($ Number of dosage units available $) /$

(Maximum number of dosage units consumed in one day)

Days' supply remaining was the outcome variable of interest. It was calculated using the number of dosage units remaining, that is, the amount of unused medication returned in the take-back event.

Days' supply dispensed was used as a predictor variable for the days' supply remaining, as larger amounts prescribed (and thus dispensed) permit larger amounts to remain. Days' supply dispensed was calculated using the number of dosage units originally dispensed, as opposed to the number of dosage units remaining.

Effects of three medication characteristics on the amount of medication returned were explored: combination, formulation, and directions for use. Each returned prescription was identified by its drug name and DEA schedule (i.e., C-II or $\mathrm{C}$-III). Each drug then was categorized by active ingredient(s) $(0=$ combination, $1=$ single-entity $)$ and formulation $(0=$ short-acting, $1=$ long-acting/extended-release). Longacting and extended-release products included various formulations that deliver a short-acting opioid in a delayed manner and methadone, which exhibits a long half-life and duration of action. From the prescription label, directions for use were identified as either on a scheduled or "as needed" $(\mathrm{PRN})$ basis $(0=$ as needed, $1=$ scheduled $)$.

\subsection{Data Analysis}

Statistical analysis was conducted using SPSS (v. 19, IBM Corporation, Somers, NY, USA). Descriptive statistics were calculated for the number of dosage units remaining and dispensed, the days' supply remaining and dispensed, and the percent remaining.

Linear regression was used to identify predictors of days' supply remaining. Three models were constructed for C-II prescriptions; each included days' supply dispensed and one of the three medication characteristics. Models were constructed in this way due to multicollinearity of the three variables used to characterize the medications. The single model constructed for C-III prescriptions included only days' supply dispensed and whether the medication was prescribed in a scheduled or PRN basis. All returned prescriptions that contained C-III medications were shortacting, combination products; therefore, formulation and active ingredient variables could not be analyzed.
In examining the data, 12 prescriptions were identified as having a days' supply remaining greater than the days' supply dispensed (i.e., a negative difference in days' supply). These prescriptions did not follow the logical assumption that the medications returned for disposal were the medications dispensed originally, and were excluded from the regression analysis. The data did not follow a normal distribution; however, two sensitivity analyses were run to corroborate the conclusions reached with the results of the models run in this study. Assumptions of linear regression were tested using variance inflation factor (VIF), Durbin-Watson test for autocorrelation, and visual inspection of residuals. A weighted least squares model was run to adjust for heteroscedasticity; but no benefit was found for this model compared to the ordinary least squares model.

\section{Results}

As noted in the methods, this study describes 605 prescriptions for opioid pain medications. These 605 prescriptions represented 11 unique opioid pain medications (Table 1). Of the 11 opioid pain medications identified, nine were C-II controlled substances. They accounted for $37.9 \%$ of all returned prescriptions and $47.6 \%$ of all returned

Table 1 Aggregate quantities returned by medication

\begin{tabular}{|c|c|c|}
\hline Medication $^{\mathrm{a}}$ & $\begin{array}{l}\text { Prescriptions } \\
N(\%)\end{array}$ & $\begin{array}{l}\text { Dosage units } \\
N(\%)\end{array}$ \\
\hline All C-II & $229(37.9)$ & $6763.5(46.7)$ \\
\hline Fentanyl transdermal $^{\mathrm{c}}$ & $21(3.5)$ & $133(0.9)$ \\
\hline Hydromorphone & $1(0.2)$ & $60(0.4)$ \\
\hline Meperidine (pethidine) & $1(0.2)$ & $4(0.0)$ \\
\hline Methadone $^{c}$ & $10(1.7)$ & $422(2.9)$ \\
\hline Morphine & $12(2.0)$ & $571(3.9)$ \\
\hline Morphine $\mathrm{SR}^{\mathrm{c}}$ & $10(1.7)$ & $273(1.9)$ \\
\hline Oxycodone & $26(4.3)$ & $1254(8.7)$ \\
\hline Oxycodone $\mathrm{ER}^{\mathrm{c}}$ & $25(4.1)$ & $1117(7.7)$ \\
\hline Oxycodone/APAP or /ASA & $123(20.3)$ & $2929.5(20.2)$ \\
\hline All C-III & $376(62.1)$ & $7713.5(53.3)$ \\
\hline Codeine/APAP & $103(17.0)$ & $1978.5(13.7)$ \\
\hline Hydrocodone/APAP & $273(45.1)$ & 5735 (39.6) \\
\hline Total & $605(100)$ & $14,477(100)$ \\
\hline
\end{tabular}

C-II (Schedule II) and C-III (Schedule III) refer to the controlled substance schedule designated by the Drug Enforcement Administration

APAP acetaminophen, ASA aspirin

a Combination products were designated by two drug entities separated by "/" (e.g., oxycodone/APAP)

b 0.5 dosage unit was recorded for any solid dosage form that was split in half and for $2.5 \mathrm{~mL}$ of a liquid dosage form

c A long-acting (methadone) or sustained- and extended-release product 
Table 2 Mean quantities returned by medication

\begin{tabular}{|c|c|c|c|c|c|}
\hline Medication $^{a}$ & $\begin{array}{l}\text { Dosage units } \\
\text { dispensed } \\
\text { Mean (SD) }\end{array}$ & $\begin{array}{l}\text { Dosage units } \\
\text { remaining } \\
\text { Mean (SD) }\end{array}$ & $\begin{array}{l}\% \text { Dosage units } \\
\text { remaining } \\
\text { Mean }(\mathrm{SD})\end{array}$ & $\begin{array}{l}\text { Days supply } \\
\text { dispensed } \\
\text { Mean (SD) }\end{array}$ & $\begin{array}{l}\text { Days supply } \\
\text { remaining } \\
\text { Mean (SD) }\end{array}$ \\
\hline All C-II & $56.5(60.5)$ & $29.5(37.8)$ & $58.1 \%(33.1)$ & $14.5(18.3)$ & $7.3(8.8)$ \\
\hline Fentanyl transdermal $^{\mathrm{b}}$ & $11.0(6.7)$ & $6.3(4.2)$ & $64.4 \%(31.6)$ & $31.8(20.8)$ & $18.5(13.1)$ \\
\hline Hydromorphone & $60.0 \mathrm{~N} / \mathrm{A}$ & $60.0 \mathrm{~N} / \mathrm{A}$ & $100 \%$ N/A & $10.0 \mathrm{~N} / \mathrm{A}$ & $10.0 \mathrm{~N} / \mathrm{A}$ \\
\hline Meperidine (pethidine) & $5.0 \mathrm{~N} / \mathrm{A}$ & $4.0 \mathrm{~N} / \mathrm{A}$ & $80.0 \% \mathrm{~N} / \mathrm{A}$ & $0.4 \mathrm{~N} / \mathrm{A}$ & $0.3 \mathrm{~N} / \mathrm{A}$ \\
\hline Methadone $^{\mathrm{b}}$ & $198.6(103.1)$ & $42.2(36.6)$ & $21.3 \%(14.8)$ & $25.3(12.3)$ & $5.4(4.6)$ \\
\hline Morphine & $61.8(51.6)$ & $47.6(50.3)$ & $71.3 \%(21.9)$ & $14.3(12.1)$ & $8.9(7.6)$ \\
\hline Morphine $\mathrm{SR}^{\mathrm{b}}$ & $53.0(21.2)$ & $27.3(15.5)$ & $57.1 \%(30.2)$ & $27.9(9.6)$ & $14.8(8.2)$ \\
\hline Oxycodone & $79.2(66.0)$ & $48.2(44.1)$ & $68.4 \%(40.4)$ & $20.8(35.7)$ & $9.8(9.2)$ \\
\hline Oxycodone $\mathrm{ER}^{\mathrm{b}}$ & $74.0(85.4)$ & $44.7(75.3)$ & $50.6 \%(23.8)$ & $23.8(9.4)$ & $12.2(8.0)$ \\
\hline Oxycodone/APAP or /ASA & $44.5(33.1)$ & $23.8(22.3)$ & $57.6 \%(33.5)$ & $6.6(9.0)$ & $3.4(5.2)$ \\
\hline All C-III & $31.7(22.4)$ & $20.5(17.9)$ & $65.7 \%(30.4)$ & $4.3(4.8)$ & $2.7(3.7)$ \\
\hline Codeine/APAP & $29.1(18.4)$ & $19.2(14.7)$ & $67.8 \%(27.1)$ & $3.6(3.6)$ & $2.4(2.9)$ \\
\hline Hydrocodone/APAP & $32.7(23.7)$ & $21.0(18.9)$ & $64.9 \%(31.5)$ & $4.5(5.2)$ & $2.8(3.9)$ \\
\hline Total & $41.1(42.9)$ & $23.9(27.5)$ & $62.8 \%(31.6)$ & $8.1(12.8)$ & $4.4(6.5)$ \\
\hline
\end{tabular}

dosage units. C-IIs included short- and long-acting/extended-release formulations, as well as single-entity and combination products. Notably, all C-II combination products were oxycodone-containing products, and accounted for $20 \%$ of all returned prescriptions. The remaining two opioid pain medications identified in the sample were C-III controlled substances; both were shortacting, combination products. In contrast to the C-II products, however, these two C-III products accounted for the majority of analyzed prescriptions $(62.1 \%)$ and aggregate number of dosage units $(53.3 \%)$ returned for disposal.

When C-II and C-III medications are compared (Table 2), results showed that C-IIs were dispensed and returned with a greater number of dosage units $(56.6 \pm 60.5$ vs. $31.7 \pm 22.4, p<0.001 ; 29.5 \pm 37.8$ vs. $20.5 \pm 17.9, p<0.001$, respectively) and were dispensed and returned with a larger days' supply (14.5 \pm 18.3 vs. $4.3 \pm 4.8, p<0.001 ; 7.3 \pm 8.8$ vs. $2.7 \pm 3.7, p<0.001$, respectively). C-II medications were returned with a smaller percentage of dosage units remaining when compared with C-IIIs $(58.1 \% \pm 33.1$ vs. $65.7 \% \pm 30.4$, $p=0.004)$. The difference between the days' supply dispensed and the days' supply remaining represents the days' supply used by the patient prior to disposal. In this sample, patients used a 7-day supply of C-II prescriptions, and a 1.5-day supply of C-III medications.

\subsection{Drug Characteristics}

Four long-acting/extended-release products were included in the returned medications; they accounted for approximately $11 \%$ of all prescriptions and all dosage units returned for disposal (Table 1). Analysis of dosage units and days' supply (Fig. 1) showed that smaller amounts of short-acting medications were dispensed and returned for disposal compared with long-acting/extended-release products. In this sample, patients used a 2.5 days' supply of short-acting medications versus a 14 days' supply of longacting/extended-release products. Short-acting medications were returned for disposal with a significantly larger percentage of the dispensed amount remaining, compared with long-acting/extended-release products (64.2 $\pm 31.6 \%$ vs. $51.5 \pm 29.5 \%, p=0.002$, not shown in figure).

Three combination products, containing hydrocodone, oxycodone and codeine, accounted for $82.4 \%$ of the prescriptions and $73.5 \%$ of the dosage units returned for disposal (Table 1). Smaller amounts of combination medications were dispensed and returned for disposal when compared with single-entity products (Fig. 1). Combination products were returned with a larger percentage of the dispensed amount remaining compared with single-entity products; however, this difference was not statistically significant.

Medications prescribed to be taken "as needed" were dispensed and returned with a smaller number of dosage units and days' supply, when compared with medications prescribed to be taken on a schedule. However, "as needed" prescriptions were returned with a greater percent of medication remaining compared with those taken on a schedule; again, this difference was not statistically significant.

\subsection{Predictive Factors}

In light of the systematic differences observed regarding the days' supply of medication dispensed, multivariate models were constructed to compare how selected 
a

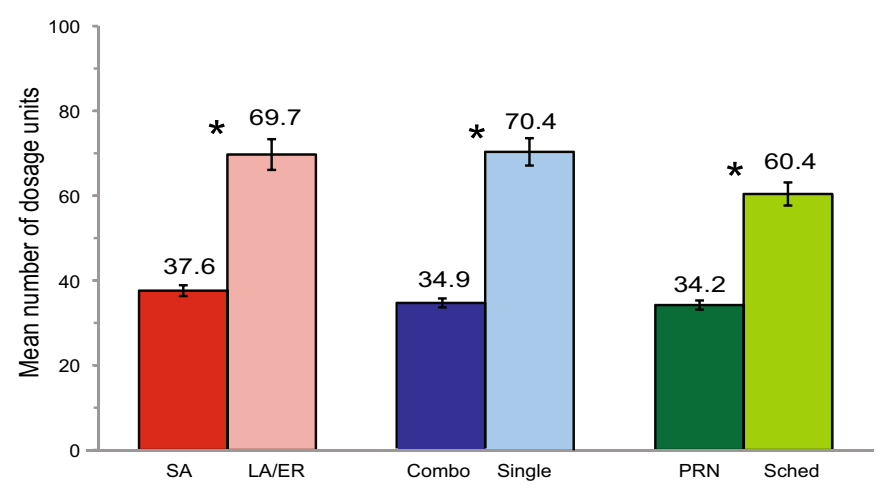

C

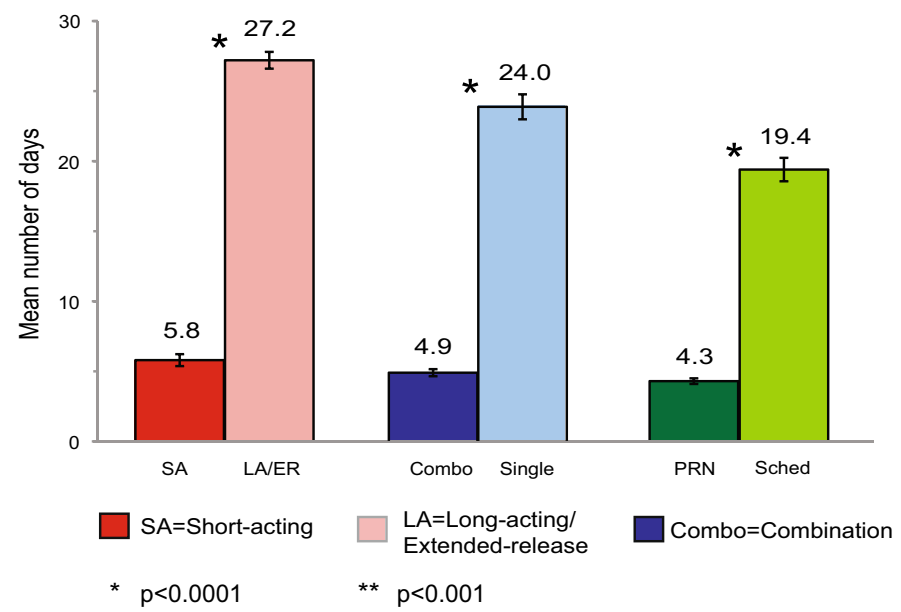

b

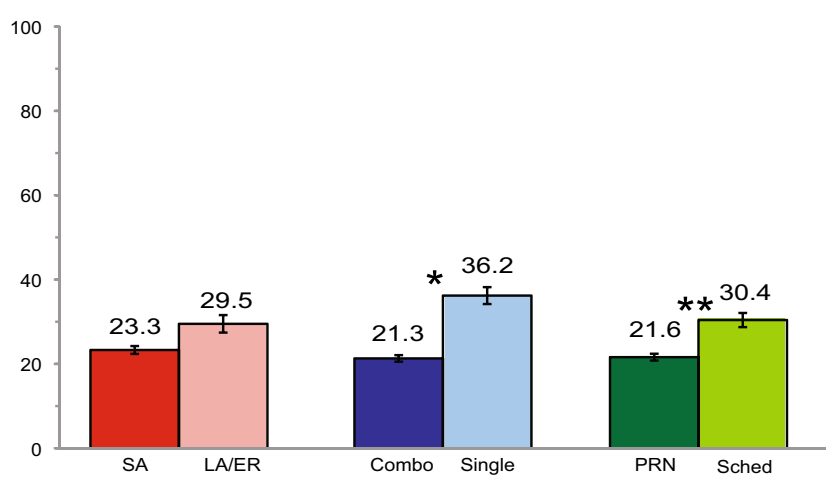

d

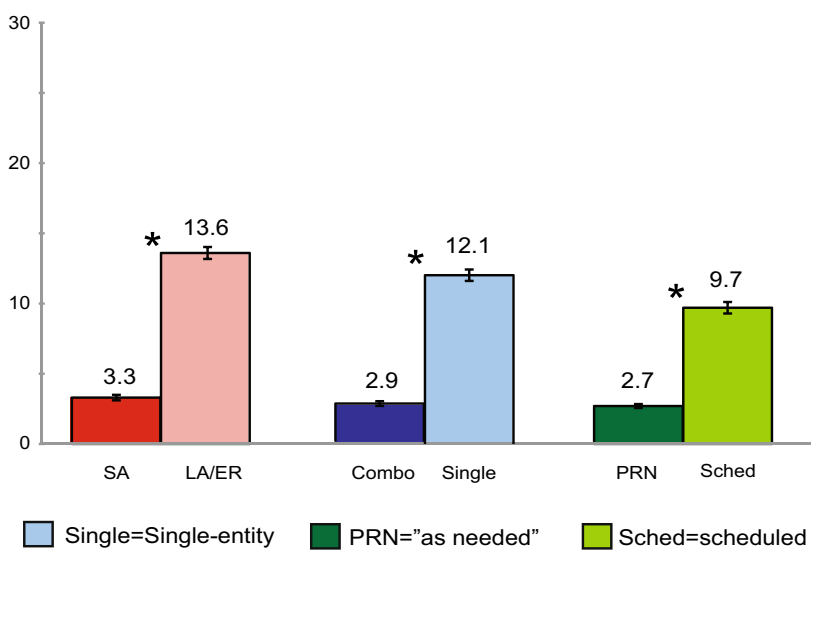

Fig. 1 Comparisons of drug characteristics. a Dosage units dispensed. b Dosage units remaining. c Days supply dispensed. d Days supply remaining

medication characteristics predicted the days' supply of unused medication returned for disposal. Four models were analyzed, three for C-II prescriptions and one for C-III prescriptions (Table 3).

All models showed that days' supply of medication dispensed was a strong predictor of days' supply remaining. An increase of one-day supply dispensed resulted in an additional quarter- (Model 1; $B=0.229$ ) to half- (Model 4; $B=0.494)$ day supply returned for disposal.

Focusing on C-II medications, a greater days' supply remaining was predicted by long-acting/extended-release products, single-entity active ingredients, and directions to take on a scheduled basis. When compared with shortacting medications, a 4.7 greater days' supply of longacting medications was predicted to remain for disposal (Model 1). When compared with combination products, a 4.3 greater days' supply of single-entity products was predicted to remain for disposal (Model 2). Finally, when compared with prescriptions taken on a scheduled basis, a 4.5 greater days' supply of prescriptions taken "as needed" remained for disposal (Model 3). In contrast to C-II medications, directions for use was not predictive of the days' supply remaining for C-III medications (Model 4).

The study models predicted $43 \%$ (Model 1) to $65 \%$ (Model 4) of the variability in the days' supply of medication returned for disposal. Notably, the strongest model, which predicts returned C-III medications, was driven by the days' supply of medication dispensed.

Sensitivity analyses of both the log transformed outcome variable and a reconceptualized outcome variable (the percent of medication remaining) that accounts for the amount of medication dispensed indicate that the days' supply dispensed is the strongest predictor of the amount of medication remaining. The decision to report the results of the days' supply remaining models was based on the clinical relevance and interpretability of the results.

\section{Discussion}

Three findings of this study are particularly relevant to prevention of nonmedical use of prescription opioids. First, 
Table 3 Regression results predicting days' supply remaining
${ }^{\text {a }}$ Formulation: $0=$ shortacting, $1=$ long-acting/ extended-release

b Active-ingredients: $0=$ combination, $1=$ singleentity

c Directions for use: $0=$ "as needed", 1 = scheduled

\begin{tabular}{|c|c|c|c|c|c|}
\hline & B & $95 \% \mathrm{CI}$ & $p$ & $\beta$ & VIF \\
\hline \multicolumn{6}{|l|}{ C-II medications } \\
\hline \multicolumn{6}{|l|}{ Model 1} \\
\hline Formulation $^{\mathrm{a}}$ & 4.703 & $2.547-6.859$ & $<0.001$ & 0.245 & 1.246 \\
\hline $\begin{array}{l}\text { Days' supply dispensed } \\
R^{2}=0.434(d f=219)\end{array}$ & 0.244 & $0.190-0.297$ & $<0.001$ & 0.512 & \\
\hline \multicolumn{6}{|l|}{ Model 2} \\
\hline Active ingredients ${ }^{\mathrm{b}}$ & 4.286 & $2.269-6.303$ & $<0.001$ & 0.244 & 1.292 \\
\hline $\begin{array}{l}\text { Days' supply dispensed } \\
R^{2}=0.431(d f=219)\end{array}$ & 0.240 & $0.186-0.295$ & $<0.001$ & 0.505 & \\
\hline \multicolumn{6}{|l|}{ Model 3} \\
\hline Directions for use ${ }^{c}$ & 4.502 & $2.398-6.607$ & $<0.001$ & 0.257 & 1.417 \\
\hline $\begin{array}{l}\text { Days' supply dispensed } \\
R^{2}=0.432(d f=219)\end{array}$ & 0.229 & $0.172-0.26$ & $<0.001$ & 0.482 & \\
\hline \multicolumn{6}{|l|}{ C-III medications } \\
\hline \multicolumn{6}{|l|}{ Model 4} \\
\hline Directions for use ${ }^{c}$ & -0.024 & $-0.561-0.513$ & 0.93 & -0.003 & 1.015 \\
\hline $\begin{array}{l}\text { Days' supply dispensed } \\
R^{2}=0.646(d f=362)\end{array}$ & 0.494 & $0.456-0.532$ & $<0.001$ & 0.804 & \\
\hline
\end{tabular}

opioid prescriptions returned for disposal had greater than $60 \%$ of the amount dispensed remaining unused. Second, drug utilization differed by drug characteristics. Notably, short-acting C-II and C-III combination opioids accounted for greater than $80 \%$ of the prescriptions returned for disposal. And finally, the day supply dispensed was the strongest predictor of day supply remaining, regardless of other drug characteristics.

Of the strategies laid out in the ONDCP's Plan, the findings of this study are most relevant to education and disposal. Prescriber education, through continuing education, school curricula and resources such as REMS, should emphasize the importance of the quantity of medication prescribed and subsequently dispensed. Quantities prescribed should reflect the clinical need of the patient [1].

Similarly, prescriber education should acknowledge differences in use based on drug characteristics. For example, patients used a 2-week supply of long-acting/extended-release medications versus a 2.5-days' supply of short-acting medications. Notably, short-acting medications, particularly hydrocodone- and oxycodone-containing products, constituted a large proportion of the prescriptions returned for disposal. As such, prescriber education should encompass both short- and long-acting opioid-containing products and their uses in acute and chronic pain.

This study showed that including data collection as a component of disposal programs offers a unique perspective on unused prescription medication. ONDCP recognized disposal programs as important in reducing diversion of prescription opioids. However, few published studies have evaluated the effect of disposal programs. Data from a disposal program that includes quantities dispensed and returned provides insight into a largely unknown contributor to diversion. These findings can shed light on actual usage patterns and identify areas warranting future study.

Data from take-back programs can also be used to monitor the effects of other initiatives aimed at reducing nonmedical use of prescription opioids. Longitudinally, these data reveal trends in amounts of leftover medication and utilization. Similarly, they may augment efforts to evaluate the effects of policy changes, such as the reclassification of hydrocodone as a C-II [16], which went into effect on 6 October 2014. Longitudinal studies could potentially show changes in the utilization of hydrocodone products returned for disposal before and after the policy change. It would be interesting to see how prescriptions for other medications change as well. ONDCP's support of disposal programs should include a plan for collecting data from disposal programs as indicators for diversion potential and evaluating effects of disposal programs.

Like all studies, this study has limitations. First, patients dropping off medication for disposal are self-selecting and may not reflect the general population. Second, it is possible a portion of the returned medication was diverted prior to collection for disposal, resulting in an overestimation of the amount of medication used by the patient for medical purposes. However, it is safe to say that of the returned prescriptions the amount of medication used was less than the amount prescribed. Third, findings of this study are limited by geographical region and cross-sectional design. Multiple studies by the Centers for Disease 
Control and Prevention (CDC) and NCDI have recognized regional differences in prescription opioid abuse and misuse $[3,6,12,13]$. This study should be replicated in other regions and conducted longitudinally to identify patterns across geography and time, respectively. Finally, the medication characteristics were limited to the information present on the medication bottle at disposal. Future studies should include additional factors that may further characterize the patients and prescribers associated with unused medication.

In summary, we found the days' supply of medication dispensed to be the strongest predictor of the days' supply of medication remaining for disposal. Prescribers should consider this while writing prescriptions for opioids of any kind-C-II or C-III, long- or short-acting, combination or single entity. Further investigation of different drug characteristics may inform prescribing practices and reduce leftover prescription opioid medication.

Acknowledgments This project was supported by the Clinical and Translational Science Award (CTSA) program, previously through a National Center for Research Resources (NCRR) Grant 1UL1RR025011, and now by the National Center for Advancing Translational Sciences (NCATS) Grant 9U54TR000021. The content is solely the responsibility of the authors and does not necessarily represent the official views of the NIH. Grace Welham had full access to all of the data in the study and takes responsibility for the integrity of the data and the accuracy of the data analysis. The authors have no conflicts of interest to disclose.

Open Access This article is distributed under the terms of the Creative Commons Attribution Noncommercial License which permits any noncommercial use, distribution, and reproduction in any medium, provided the original author(s) and the source are credited.

\section{References}

1. Bates C, Laciak R, Southwick A, Bishoff J. Overprescription of postoperative narcotics: a look at postoperative pain medication delivery, consumption and disposal in urological practice. J Urol. 2011;185(2):551-5.

2. Braden JB, Fan MY, Edlund MJ, Martin BC, DeVries A, Sullivan MD. Trends in use of opioids by noncancer pain type 2000-2005 among Arkansas Medicaid and HealthCore enrollees: results from the TROUP study. J Pain. 2008;9(11):1026-51035.

3. CDC. Unintentional poisoning deaths: United States, 1999-2004. MMWR. 2007;56(5).

4. CDC. QuickStats: age-adjusted death rates per 100,000 population for the three leading causes of injury death: United States, 1979-2006. MMWR, vol. 58. Atlanta: CDC; 2009. p. 675.
5. CDC. Adult use of prescription opioid pain medications: Utah, 2008. MMWR, vol. 59. Atlanta: CDC; 2010. p. 153-5157.

6. CDC. Vital signs: overdoses of prescription opioid pain relievers: United States, 1999-2008. MMWR, vol. 60. Atlanta: CDC; 2011. p. $1-56$.

7. Disposal of controlled substances, 21 CFR $\$ 1300$ (2014).

8. Edlund MJ, Martin BC, Devries A, Fan MY, Braden JB, Sullivan MD. Trends in use of opioids for chronic noncancer pain among individuals with mental health and substance use disorders: the TROUP study. Clin J Pain. 2010;26(1):1-58.

9. Glassmeyer ST, Hinchey EK, Boehme SE, Daughton CG, Ruhoy IS, Conerly O, Daniels RL, Lauer L, McCarthy M, Nettesheim TG, Sykes K, Thompson VG. Disposal practices for unwanted residential medications in the United States. Environ Int. 2009;35(3):566-5572.

10. Korff MV, Saunders K, Thomas Ray G, Boudreau D, Campbell C, Merrill J, Sullivan MD, Rutter CM, Silverberg MJ, BantaGreen C, Weisner C. De facto long-term opioid therapy for noncancer pain. Clin J Pain. 2008;24(6):521-5527.

11. McManus P, Mant A, Birkett D, Hemming M, Lindner J. Examining the adequacy of quantities available for subsidized antidepressant prescriptions in Australia. Pharmacoepidemiol Drug Saf. 1999;8(3):191-5195.

12. NCDI. National Center for Drug Intelligence. National drug threat assessment. 2010.

13. NCDI. National Center for Drug Intelligence. National drug threat assessment. 2011.

14. ONDCP. Epidemic: responding to America's prescription drug abuse crisis. Washington, DC; 2011.

15. SAMHSA. Quick statistics from drug and alcohol services. Rockville: SAMHSA.

16. Schedules of controlled substances: rescheduling of hydrocodone combination products from schedule III to schedule II, 79 FR 49661 (2014).

17. Substance Abuse and Mental Health Services Administration. Results from the 2008 National Survey on Drug Use and Health: National Findings, vol. Office of Applied Studies. Rockville, MD; 2009.

18. Substance Abuse and Mental Health Services Administration. Treatment Episodes Data Set (TEDS). Highlights-2007. National Admissions to Substance Abuse Treatment Services. In: DHHS Publication No 09-4360 editor. Rockville, MD; 2009.

19. Substance Abuse and Mental Health Services Administration. Treatment Epidoses Data Set (TEDS) 1999-2009. National Admissions to Substance Abuse Treatment Services In: DHHS Publication No 11-4646 editor. Rockville, MD; 2011.

20. Warner M, Chen LH, Makuc DM. Increase in fatal poisonings involving opioid analgesics in the United States, 1999-2006. NCHS data brief, vol. 22. Hyattsville: National Center for Health Statistics; 2009.

21. Wilensky J, Fiscella RG, Carlson AM, Morris LS, Walt J. Measurement of persistence and adherence to regimens of IOP-lowering glaucoma medications using pharmacy claims data. Am J Ophthalmol. 2006;141(1 Suppl):S28-533. 